\title{
RELEVÂNCIA ECONÔMICA DOS BENEFÍCIOS PREVIDENCIÁRIOS NOS MUNICÍPIOS DA REGIÃO COREDE CELEIRO/RS
}

\section{ECONOMIC RELEVANCE OF SOCIAL SECURITY BENEFITS IN THE CITIES OF COREDE CELEIRO/RS}

\author{
RELEVANCIA ECONÓMICA DE LOS BENEFICIOS SOCIALES EN LAS \\ MUNICIPALIDADES DE COREDE CELEIRO/RS
}

\author{
Romualdo Kohler ${ }^{1}$ \\ Karine Matuchevski Balzan ${ }^{2}$ \\ João Vitor Moraes Ribas ${ }^{3}$
}

\begin{abstract}
RESUMO
Este artigo tem como objetivo investigar e debater sobre a relevância econômica dos benefícios pagos pela Previdência Social Federal na renda dos municípios brasileiros, em especial nos de pequeno porte. Parte-se da premissa de que no local os fundamentos teóricos diferem-se dos da macroeconomia nacional, por se tratar de uma economia aberta por excelência, com livre fluxo de bens, serviços, rendas, capitais e fatores de produção. Para tal abordagem, epigrafou-se as teorias da Base Exportadora, da Base Econômica e da proposição de Kohler com ênfase na endogeneidade da moeda no território e na diferenciação entre Produto e Renda. Com vistas ao enquadramento metodológico, trata-se de uma pesquisa exploratória, bibliográfica e quantitativa, com o trato estatístico de dados secundários oficiais da Região do COREDE Celeiro/RS, composta por 21 municípios, todos com menos de 25.000 habitantes. Como resultados observou-se a grandeza relativa dos benefícios previdenciários na composição da Renda Municipal, para além da forte correlação, em especial, entre estas transferências públicas e o setor terciário nos municípios amostrais.
\end{abstract}

Palavras-chave: Renda Municipal. Teoria da Base Econômica. Endogeneidade da Moeda. Benefícios Previdenciários. Desenvolvimento Regional.

\footnotetext{
${ }^{1}$ Doutor em Administração. Professor Permanente no Programa de Pós-Graduação em Desenvolvimento Regional - Mestrado e Doutorado. Universidade Regional do Noroeste do Estado do Rio Grande do Sul (UNIJUÍ). Ijuí. Rio Grande do Sul. Brasil. ORCID: https://orcid.org/0000-0003-2083-9279. E-mail: romualdo@unijui.edu.br

${ }^{2}$ Mestre em Engenharia de Produção - Doutoranda do Programa de Pós-Graduação em Desenvolvimento Regional - Mestrado e Doutorado. Universidade Regional do Noroeste do Estado do Rio Grande do Sul (UNIJUÍ). Ijuí. Rio Grande do Sul. Brasil. ORCID: https://orcid.org/0000-0002-9980-146X. E-mail: kmatucha@hotmail.com

${ }^{3}$ Bolsista PROBIC/FAPERGS. Acadêmico do Curso de Ciência da Computação. Universidade Regional do Noroeste do Estado do Rio Grande do Sul (UNIJUÍ). Ijuí. Rio Grande do Sul. Brasil. ORCID: https://orcid.org/0000-0003-3669-2240. E-mail: joaovitor ribas@hotmail.com
} 


\begin{abstract}
This academic article has as goal to investigate and debate regarding the economic importance of the benefitis which are paid from the Federal Social Security in the income of the brazilian counties, especially in the small ones. It is assumed from the premise that in the local framework the theorical fundamentals are quite different from the national macroeconomy, because it is an open economy for excellence, with free flow of assets, services, incomes, capital and production factors. For such approach, it was epigraphated the theories of the Exporter Base, the Economic Base and the proposition of Kohler with emphasis in the endogeneity of the currency in the territory and in the diferentiation between Product and Income. Taking in count the metodological framework. It is about an exploratory, bibliographic and quantitative reasearch with the estatistic treatment of the oficial data from the COREDE Celeiro/RS Region, which is composed of 21 counties, each one with less than 25000 inhabitants. As result, it was observed the relative quantity of the social security benefits on the composition of the Municipal Income, beyond the strong correlation, in special, between these public transferences and the tertiary sector in the sample counties.
\end{abstract}

Key-Words: Municipal Income. Economic Base Theory. Currency Endogeneity. Social Security Benefits. Regional Development.

\title{
RESUMEN
}

Este artículo tiene como meta investigar y debatir sobre el relavancia económica de los beneficios pagados por la Seguridad Social Federal en la renta de las municipalidades brasileñas, en especial en las pequeñas. Es asumido qué en la localidad los fundamentos teóricos son diferentes de la macroeconomía nacional, por qué son economías abiertas por excelencia, con libre flujo de bienes, servicios, ingresos, capitales y factores de produción. Para tal enfoque, se ha destacado las teorías de la Base Exportadora, de la Base Económica y de la proposición de Kohler con énfasis en la endogeneidad de la moneda en el territorio y en la diferenciación entre Producto y Renta. En vista del marco metodológico, se trata de un estudio exploratorio, bibliográfico y cuantitativo, con el tratamiento estadístico de datos secundarios oficiales de la Región de lo COREDE Celeiro/RS, compuesta por 21 municipalidades, todos con menos de 25.000 habitantes. Como resultados se ha observado la grandeza relativa de los beneficios de la seguridad social en la composición de la Renta Local, además de la fuerte correlación, en particular, entre estas transferencias públicas y el sector terciario en las municipalidades de la muestra.

Palabras Clave: Renta Local. Teoría de la Base Económica. Endogeneidad de la Moneda. Beneficios de la Seguridad Social. Desarrollo Regional.

Como citar este artigo: KOHLER; Romualdo; BALZAN, Karine Matuchevski; RIBAS, João Vitor Moraes. Relevância econômica dos benefícios previdenciários nos municípios da região COREDE Celeiro/RS. DRd - Desenvolvimento Regional em debate, v. 10, p. 932-951, 11/08/2020. DOI: https://doi.org/10.24302/drd.v10i0.2891 
Artigo recebido em: $31 / 05 / 2020$

Artigo aprovado em: 09/07/2020

Artigo publicado em: 11/08/2020

\section{INTRODUÇÃO}

Em nossa contemporaneidade, a abordagem acerca dos benefícios pagos pela Previdência Social do Governo Federal é muito analisada e debatida pelos enfoques fiscal e orçamentário. Entretanto, a Previdência não é somente uma rubrica contábil, antes disso é uma política de seguridade social, onde o Estado busca o amparo e a assistência ao cidadão na velhice, na doença e, em casos especiais, no desemprego.

No caso brasileiro, a Previdência Social obteve uma maior abrangência a partir da Constituição Federal de 1988, visto que, na alcunha de "Constituição Cidadã", avançou na garantia de renda aos trabalhadores urbanos e rurais, idosos, acidentados, doentes, inválidos e dependentes pensionistas.

Entretanto, na complexidade das ciências afloram outras abordagens relevantes, nas mais diversas áreas. Em termos econômicos, os recursos transferidos às famílias são, também, uma forma redistributiva de renda, bem como, ramificam efeitos na produção, pela circulação dos valores monetários.

E é, neste contexto, que o trabalho procura pinçar para o debate acadêmico os efeitos econômicos dos benefícios pagos aos cidadãos em seus lócus de vida, os municípios, em especial, medindo sua grandeza na relação com o produto e a renda locais.

Para este feito, o artigo epigrafa teorias que buscam avaliar/explicar o desempenho de economias locais, aproximando as teorias da Base Exportadora e da Base Econômica com a proposição trazida por Kohler com ênfase na endogeneidade da moeda local e na diferenciação entre Produto e Renda (KOHLER, 2018). De pronto, vale registrar a premissa de que as economias dos municípios são particulares e se diferenciam de economias nacionais por serem abertas por excelência, pelo livre fluxo com seu exterior, de bens, serviços, fatores de produção, rendas e capitais.

Para verificação empírica dos efeitos dos benefícios previdenciários na economia de municípios, à luz dos aportes teóricos referenciados, pinçou-se a Região do COREDE Celeiro, localizada no noroeste do Estado do Rio Grande do Sul e que abarca 21 municípios de pequeno porte, ou seja, com menos de 25.000 habitantes.

Assim, seguem-se aspectos da Previdência Social, das teorias acerca da economia de municípios, da metodologia utilizada na pesquisa, da caracterização da Região do COREDE Celeiro, dos resultados e discussão e, no fecho, as considerações finais. 


\section{A PREVIDÊNCIA SOCIAL NO BRASIL E SUA RELAÇÃO COM O DESENVOLVIMENTO}

No Brasil, a Previdência Social faz parte da Seguridade Social e é responsável pelas ações e serviços que visam garantir o bem-estar e a justiça social através da saúde, da assistência e da previdência em si. A Previdência traduz-se em "[...] uma poupança forçada, imposta ao cidadão para que este possua condições financeiras para manter a sua capacidade de consumo quando não mais possuir capacidade para trabalhar" (ALCÂNTARA et al., 2016, p. 269).

O início regulamentar do sistema previdenciário brasileiro, foi estabelecido pela lei Eloy Chaves em 1923 e tinha como finalidade criar as Caixas de Aposentadoria e Pensões para os ferroviários.

A Lei Eloy Chaves, de 1923, é considerada o marco legal que deu início ao atual sistema previdenciário brasileiro para os trabalhadores do setor privado. Foi responsável pela criação de caixas de aposentadorias e pensões por morte para os trabalhadores ferroviários. Cobria uma pequena parcela da população trabalhadora e seus dependentes (ALCÂNTARA et al., 2016, p. 266).

Assim, o Decreto $\mathrm{n}^{\circ}$ 4.682, de 24 de janeiro de 1923, conhecido como Lei Elói Chaves, pela autoria do projeto, abriu precedentes para que o benefício fosse estendido para outros setores da economia, através de novos sistemas.

Em 1930, foi criado o Ministério do Trabalho, Indústria e Comércio, que tinha como uma das atribuições orientar e supervisionar a Previdência Social, inclusive como órgão de recursos das decisões das Caixas de Aposentadorias e Pensões (BRASIL, 2019). O sistema CAPs, foi substituído pelos Institutos de Aposentadorias e Pensões (IAPs), centralizando pelo governo federal.

A partir de 1930, a previdência social ganhou o interesse dos trabalhadores e do Estado. O sistema tripartite de financiamento da previdência conhecido hoje foi previsto inicialmente na Constituição de 1934. A partir daí, iniciou-se um novo período, com o agrupamento das caixas de aposentadoria em grandes Institutos de Aposentadoria e Pensões (IAPs), que cobriam quase todos os empregados urbanos e trabalhadores por conta própria e seus dependentes, vinculados por categorias ocupacionais (ALCÂNTARA et al., 2016, p. 266).

Em 1960 foi criada a Lei Orgânica da Previdência Social (LOPS), que unificou os direitos estabelecidos entre os institutos criados dentro do sistema IAP (ALCÂNTARA et al., 2016). E em 1963 foi criado o Fundo de Assistência ao Trabalhador Rural - FUNRURAL pela Lei $\mathrm{n}^{\circ} 4.214$, de 2 de março. No mesmo ano a Resolução $\mathrm{n}^{\circ} 1.500$, de 27 de dezembro, do Departamento Nacional de Previdência Social, aprovou o Regimento Único dos Institutos de Aposentadoria e Pensões (BRASIL, 2019).

No ano de 1966 foi instituído o Fundo de Garantia por Tempo de Serviço - FGTS e reuniu os seis Institutos de Aposentadorias e Pensões no Instituto Nacional de Previdência Social - INPS (conhecido atualmente como INSS - Instituto Nacional de Seguridade Social). Em 1967, foi integrado o seguro de acidentes do trabalho na Previdência Social (BRASIL, 2019).

DRd - Desenvolvimento Regional em debate (ISSNe 2237-9029) 
A constituição de 1967 instituiu o salário mínimo, salário família, a proibição de diferenciação de salários por conta de sexo, cor e estado civil, jornada de trabalho de oito horas, férias remuneradas, entre outros.

Já a Constituição de 1988 determinou um conjunto de ações envolvendo saúde, assistência e previdência social chamado de Seguridade Social (BRASIL, 2019). A partir daí é que se estabelece a previdência nos termos atuais, mantendo a arrecadação entre empregadores e empregados, cabendo ao Estado organizar e distribuir os recursos.

O texto legal estabeleceu como princípios básicos a universalização da cobertura e do atendimento; a equivalência de benefícios urbanos e rurais; a seletividade na concessão; a irredutibilidade do valor das prestações previdenciárias; a equanimidade no custeio; a diversificação da base de financiamento; a descentralização e a participação da comunidade, de trabalhadores, empregadores e aposentados na gestão; a fixação do benefício mínimo que substitui o salário de contribuição ou o rendimento do trabalho em um salário mínimo (ALCÂNTARA et al., 2016, p. 268 e 269).

Com os direitos adquiridos pela Constituição de 1988, ficou mais evidente a importância dos benefícios previdenciários na composição da renda de muitas famílias, contudo acalora um debate "de dois lados", contraditório entre os que defendem os efeitos positivos dos benefícios na economia e os que focam somente na sustentabilidade do sistema.

\begin{abstract}
Por um lado, defende-se que o sistema atual desempenha um importante papel para a economia nacional, com seus efeitos sociais que contribuem para redução da pobreza. Por outro, embora se reconheça os efeitos positivos da previdência no combate à pobreza, ressalta-se que atualmente esses efeitos são inexistentes e indicam que os custos e as falhas das ações governamentais tendem a comprometer a existência futura do sistema (REIS et al., 2011, p. 5).
\end{abstract}

Sem se alongar nessa contextualização, que culminou em uma reforma previdenciária mais aprofundada em 2019 e que em seu bojo trouxe o sumo fiscalista dos vitoriosos no embate, mas para atender os propósitos desta investigação, se centra a atenção nos efeitos dos recursos previdenciários na economia dos municípios, em especial os de pequeno porte.

Neste enfoque Correio e Correio salientam que os benefícios em muitos municípios são importantes na composição da renda das famílias, possibilitando a diminuição da pobreza por meio da redistribuição de renda; no sustento de filhos e netos desempregados ou subempregados; na melhoria da qualidade de vida; e na maioria dos casos, ser uma das principais fontes de receitas para os municípios (CORREIO; CORREIO, 2015).

No mesmo sentido, Augusto e Ribeiro, já defendiam que o valor do benefício previdenciário estimula a economia dos pequenos municípios, especialmente dos menos desenvolvidos, pois estes benefícios são consumidos nos comércios locais, promovendo maior movimentação financeira, aumentado as vagas no mercado de trabalho, além, da melhoria da qualidade de vida dos aposentados e de seus dependentes (AUGUSTO; RIBEIRO, 2005).

De outra forma, deve-se considerar que, com o aumento da expectativa de vida e o baixo crescimento econômico, a importância dos benefícios previdenciários apresente maior grandeza no território:

Um estudo feito pela Associação Nacional dos Auditores Fiscais da Receita Federal (Anfip), incluído no relatório "A Previdência Social e os Municípios", revela que o atual modelo de Previdência Social -- com pagamento de aposentadorias, pensões e

DRd - Desenvolvimento Regional em debate (ISSNe 2237-9029) 
benefícios sociais -- sustenta a maior parte da economia local dos municípios, inclusive nas regiões Sudeste e Sul do país. Em 87\% das cidades, por exemplo, o valor total dos pagamentos do Instituto Nacional do Seguro Social (INSS) supera a arrecadação previdenciária, gerando renda e reduzindo a desigualdade (GUIMARÃES, 2019, p. 1).

Este cenário trouxe inspiração para dimensionar a relevância econômica dos benefícios previdenciários nos pequenos municípios brasileiros. Para tal, se avança para o debate teórico que deve permitir a iluminação necessária para um olhar mais robusto na temática.

\section{ASPECTOS TEÓRICOS DA MACROECONOMIA MUNICIPAL}

A economia local, nesta reflexão representada pelos municípios brasileiros, se reveste de contornos teóricos particulares no tocante ao dimensionamento do produto e da renda, se confrontados com os de uma economia nacional. A centralidade das divergências reside na caracterização do local como um espaço de livre fluxo econômico, ou melhor, bens, serviços, fatores de produção, rendas e capitais transitam em suas fronteiras sem nenhuma restrição.

Vale ainda frisar que o desafio de entender a economia do local se agiganta ao se constatar que é neste recorte territorial que os cidadãos se abarcam e, portanto, o entendimento de seus fluxos de produção, emprego e renda se justificam. Estes elementos são fontes para o debate acadêmico, e, assim, se pontuam as repercussões das transferências de renda aos municípios, no caso especial dos benefícios previdenciários federais.

Kohler, traz esse debate à tona, focando a análise nos fluxos monetários do território com seu exterior, defendendo as hipóteses da endogeneidade da moeda no local, da inconstância de sua velocidade de circulação e da não-neutralidade em relação ao desempenho do produto (KOHLER, 2018).

A tese da endogeneidade da oferta de moeda local conflita com as concepções teóricas das economias nacionais, já que essas definem a base monetária como uma variável exógena, visto que é função dos bancos centrais o seu dimensionamento. No local, defende o autor, a base monetária é dada pela dinâmica econômica e não por determinação das autoridades monetárias, ou melhor, o que define a quantidade de moeda no local são os fluxos monetários convergentes e divergentes com seu exterior.

Já em relação aos aspectos da inconstância da velocidade de circulação da moeda e à determinação da participação da moeda no comportamento do produto, o autor incorpora o pensamento Keynesiano, em detrimento dos clássicos, em afronta então à Lei de Say, em que a oferta cria sua própria procura e à Teoria Quantitativa da Moeda, que a moeda é neutra em relação ao produto, interferindo apenas nos níveis de preços. Keynes, a partir do Princípio da Demanda Efetiva, defendeu o oposto, com a valorização da demanda na definição da oferta. A importância do destaque da circulação da moeda é atribuída pelo enquadramento dos multiplicadores keynesianos, no caso desta reflexão, da contribuição da Renda no dimensionamento do Produto. 
Sem alongar no debate, se indica que estas definições implicam em assumir a hipótese de que a moeda tem correlação direta com a definição do produto, ou seja, a quantidade de moeda é decisiva no volume das atividades econômicas nos municípios.

Assim, com o intuito de corroborar essas premissas, Kohler usou uma balança de pagamentos adaptada da contabilidade nacional para as particularidades municipais (KOHLER, 2018). Para um especial destaque aos propósitos deste trabalho chama-se atenção à segregação das rendas em rubrica isolada na estrutura da conta de transações correntes, conforme aponta o quadro abaixo:

Quadro 1 - Balança de pagamento de município

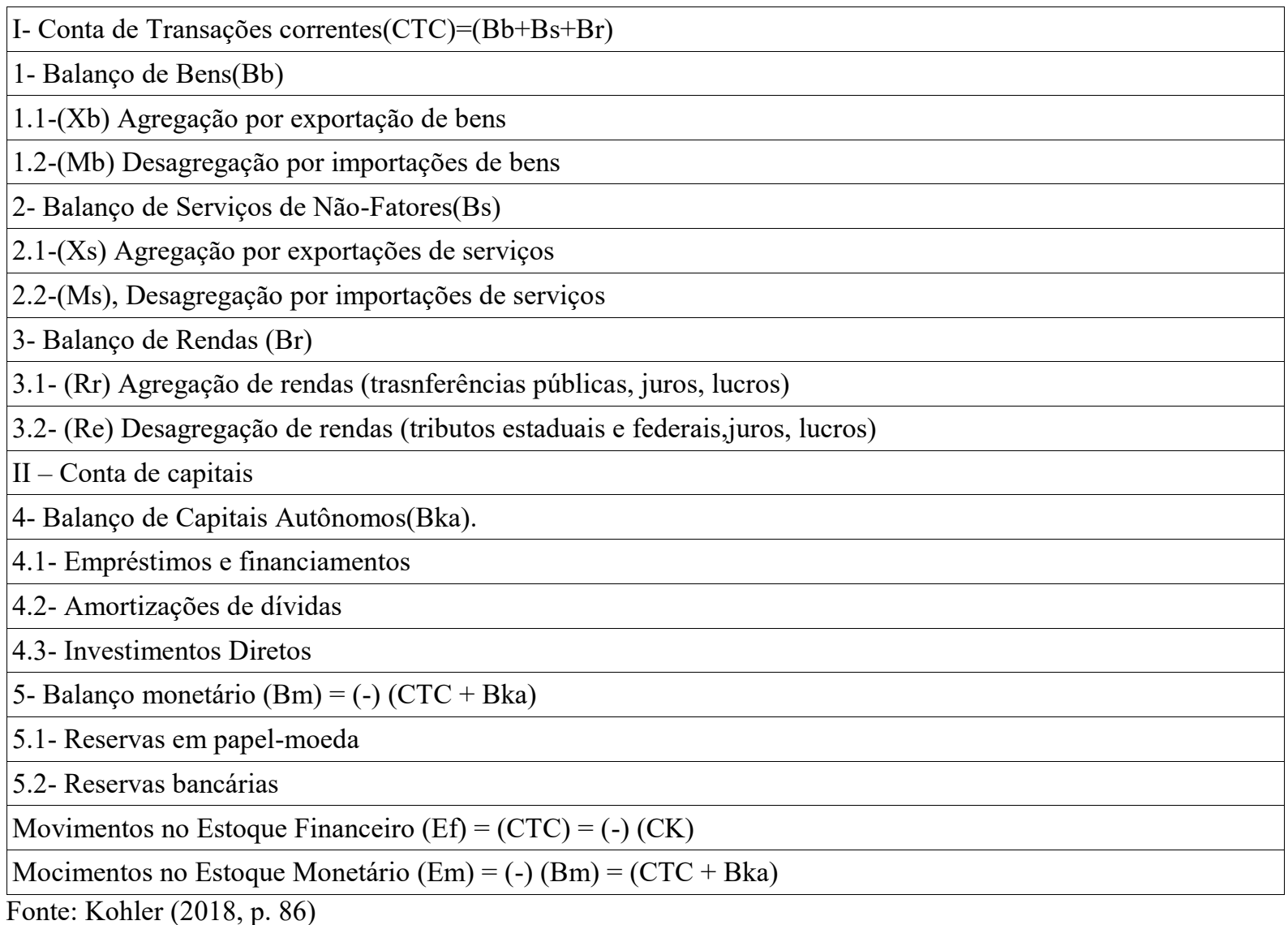

No estudo o autor simula movimentos reais e monetários na Balança de Pagamentos para defender suas teses e, assim, também corrobora duas outras teorias muito referenciadas em estudos de desenvolvimento local e regional: a Teoria da Base Exportadora, com os movimentos expressos no Balanço de Bens e Balanço de Não Fatores, e a Teoria da Base Econômica, representada pelo conjunto da Conta de Transações Correntes, adicionando, portanto, o Balanço de Rendas. A primeira, proposta por North, na década de 1950, destaca o papel das exportações de bens e serviços produtivos na dinâmica econômica local (NORTH, 1977). Enquanto que a segunda, menos propalada, assume as premissas de North, porém, segundo mostra Souza (1980), engloba, além desta, as demais variáveis independentes que explicam parcialmente de maneira significativa o nível de produto local, ou seja, incorpora os fluxos de rendas para além dos fluxos de produção. 
$\mathrm{Na}$ balança epigrafada acima, todos os fluxos com o seu exterior, reais e monetários, estão contemplados o que atribui a Teoria da Base Econômica um papel fundamental para o entendimento da endogeneidade da moeda local. Ao também assumir os preceitos keynesianos da não neutralidade da moeda, se conforma um sistema de cobertura monetária à dinâmica econômica local.

Neste cenário, a base econômica é atribuída ao setor cognominado de básico, que representa todas as atividades produtivas, acrescidas das rendas, que se corporificam nos fluxos com o exterior, portanto, decisivas na determinação da oferta de moeda. Categoriza-se, ainda, outro setor como não-básico, representado pelas atividades de produção e circulação interna no território, que tem seu desempenho condicionado à dinâmica do setor básico pela definição monetária, contudo assume um papel fundamental na definição da velocidade de circulação interna da moeda.

Para exemplificar e tornar mais didática a exposição, pode se referir hipoteticamente a um município de base agrícola que, na abundância de produção e preços, enquanto setor básico, em tese dinamiza as atividades produtivas internas, setor não-básico, pela maior disponibilidade monetária.

De outra forma, essas simulações também permitiram que Kohler discutisse a relação entre poupança e investimento, apontando diferenciação entre os recorte territoriais, local e nacional (KOHLER, 2018). Este tópico, já referenciado como fonte de controvérsias no debate econômico, se fundamenta também pelo confronto teórico entre a Lei de Say, que valoriza a oferta, e o preceito Keynesiano expresso na Teoria da Demanda Efetiva, que engrandece a demanda. No dimensionamento municipal, validado como uma economia aberta, Kohler amplia o conceito teórico de poupança, enquanto renda não consumida, para duas categorias: poupança produtiva, em identidade com o investimento; e poupança financeira, em consonância com o resultado da balança de pagamentos, portanto definidora dos saldos monetários e financeiros.

\begin{abstract}
Portanto, a poupança total de uma economia aberta é expressão desses dois movimentos gerados no fluxo de produção e rendas, produtivo e financeiro, sendo, por consequência, também uma variável ex-post. Representa assim, a geração de uma riqueza não-consumida, quer por ampliação da capacidade produtiva, quer por elevação de haveres com o exterior ou aumento das reservas monetárias. Vale frisar ainda que uma poupança financeira negativa vai comprometer proporcionalmente a poupança total, o que indica, simplesmente, que um excesso de demanda interna sobre a produção, ou de envio de rendas ao exterior, reduzem a renda total não consumida, sem necessariamente se constituir no financiamento do investimento (KOHLER, 2018, p. 246).
\end{abstract}

De outra forma, o autor também exacerbou a diferenciação entre Produto e Renda Municipal, que neste recorte espacial, à luz da Teoria da Base Econômica, corroborada pela Balança de Pagamentos Local, assume destaque pela diferença conceitual entre essas variáveis na macroeconomia municipal: enquanto o primeiro assume a conotação produtiva, a segunda se reveste de um caráter monetário.

Com estas vertentes teóricas e para atender aos propósitos nesse trabalho, vale frisar que as transferências públicas, sob a rubrica de benefícios previdenciários federais, incorporam-se à Renda Municipal e não ao Produto Municipal, embora ex-post se verifiquem efeitos diretos (gastos em empresas locais), indiretos (na cadeia produtiva) e induzidos (circulação monetária) (KOHLER, R.; GAY, 2018). 


\section{METODOLOGIA}

O presente artigo está embasado em uma pesquisa exploratória, ou seja, as informações sobre um determinado problema ou fenômeno são levantadas para amplificar o conhecimento e assim, elaborar problemas e hipóteses mais qualificadas (GIL, 2019).

Quanto ao método, a pesquisa categoriza-se como bibliográfica, visto ter sido desenvolvida com base em material já elaborado, constituído principalmente de livros e artigos científicos.

A coleta de dados centrou em estatísticas secundárias oficiais disponibilizadas para o ano de 2016, em especial, pelo Instituto Brasileiro de Geografia e Estatística - IBGE, para os números do Valor Adicionado Bruto - VAB, dos Setores e Total, e do Instituto Nacional de Seguridade Social - INSS, para os montantes dos benefícios previdenciários, o que lhe atribui a categorização de pesquisa quantitativa.

Vale frisar que o VAB se constitui em uma variável econômica que mensura a produção bruta de determinado território e se distingue do Produto Interno Bruto - PIB, pela exclusão dos tributos. Tem a vantagem de serem disponibilizadas as informações no recorte municipal, para além dos números totais, com a desagregação por setores produtivos.

Já os benefícios previdenciários, utilizados na pesquisa, abarcam os valores anuais referentes às transferências públicas pagas às famílias, por conta dos direitos constitucionais atrelados à Seguridade Social em nível federal e foram levantadas junto à Agência Regional do INSS de Ijuí/RS.

O tratamento dos dados se deu por técnicas estatísticas de correlação e regressão linear, com utilização dos recursos do excel. Nem de longe, pelos propósitos dessa investigação, objetivou-se precisões matemáticas, entretanto buscou-se com as ferramentas estatísticas indicativos para, desta forma, subsidiar leituras para corroborar os construtos teóricos.

Assim, com os testes de correlação se buscou presumir a variabilidade de um dado estatístico em relação aos movimentos de outro, visando identificar se existe alguma relação entre ambos. Os resultados se expressam pelo coeficiente de correlação e variam entre -1 e 1 , sendo que quanto mais próximo de 1 , maior a correlação negativa entre as variáveis, e quanto mais próximo de 1 , maior a correlação positiva.

O gráfico de dispersão, ou diagrama como também é conhecido, é o resultado gráfico da plotagem de pares de dados numéricos, ou seja, se trata de uma ferramenta visual que indica a existência, ou não, de relações entre variáveis em um processo e sua intensidade. Ao diagrama se pode adicionar uma linha de tendência, baseada em regressão linear, que dá referência simétrica à dispersão dos pares de dados. Quanto maior a proximidade dos pontos com a linha de tendência, maior é a capacidade explicativa da relação entre as variáveis.

Ainda, no gráfico de dispersão, foi possível apontar o coeficiente de determinação, $\mathrm{R}^{2}$, extraído de cálculo em regressão linear simples, e que pode variar no intervalo entre 0 e 1 , indicando que quanto maior o $\mathrm{R}^{2}$, mais explicativo é o modelo linear. Pode ser expresso também 
em termos percentuais, indicando que quanto mais próximo dos $100 \%$, maior é a capacidade de uma variável determinar a outra.

Como definição da amostra, no intuito da representação dos municípios brasileiros de pequeno porte, aqui referenciados com população inferior a 25.000 habitantes, se optou pelos integrantes da Região do COREDE Celeiro/RS, em que todas as unidades administrativas estão enquadradas neste extrato demográfico, conforme breve caracterização a seguir, antes da apresentação dos resultados e discussão.

\section{CARACTERIZAÇÃO DA REGIÃO DO COREDE CELEIRO/RS}

As políticas de planejamento e de desenvolvimento regional exigem muitos desafios que evidenciam a necessidade da participação efetiva da sociedade na elaboração e escolha de projetos. No Rio Grande do Sul, desde 1990, se estrutura o planejamento regional através dos Conselhos Regionais de Desenvolvimento - COREDEs, que viabilizam ações descentralizadas de planejamento, com o objetivo de promover o desenvolvimento econômico em âmbito regional. Como coloca (SILVEIRA, 2015):

\footnotetext{
Os COREDEs foram criados num contexto de afirmação da redemocratização do País e de valorização da descentralização das políticas públicas e de estímulo à participação da sociedade civil, marcas características da Constituição Federal de 1988 e reiteradas no Estado, com a Constituição Estadual de 1989. Assim, a aproximação entre governo e instituições da sociedade civil em cada região, em especial com as universidades, possibilitou, a partir de 1991, as condições para a constituição e estruturação iniciais dos COREDEs que, já em 1994, se consolidavam de forma efetiva em vinte e uma regiões do território do Rio Grande do Sul (SILVEIRA, 2015, p. 73-74).
}

O Conselho Regional de Desenvolvimento da Região Celeiro, o COREDE Celeiro, está localizado no noroeste do Estado do Rio Grande do Sul, faz fronteira com a Argentina e com o Oeste do Estado de Santa Catarina. Foi um dos últimos a ser criado no Estado, no ano de 2008, tem origem no desmembramento do COREDE Noroeste Colonial, integrante da Região Funcional 7 (RIO GRANDE DO SUL, 2017).

Os municípios integrantes do COREDE Celeiro, em número de 21, são: Barra do Guarita, Bom Progresso, Braga, Campo Novo, Chiapetta, Coronel Bicaco, Crissiumal, Derrubadas, Esperança do Sul, Humaitá, Inhacorá, Miraguaí, Redentora, Santo Augusto, São Martinho, São Valério do Sul, Sede Nova, Tenente Portela, Tiradentes do Sul, Três Passos e Vista Gaúcha, com visualização gráfica na figura abaixo. 
Figura 1 - Localização dos municípios do COREDE Celeiro.

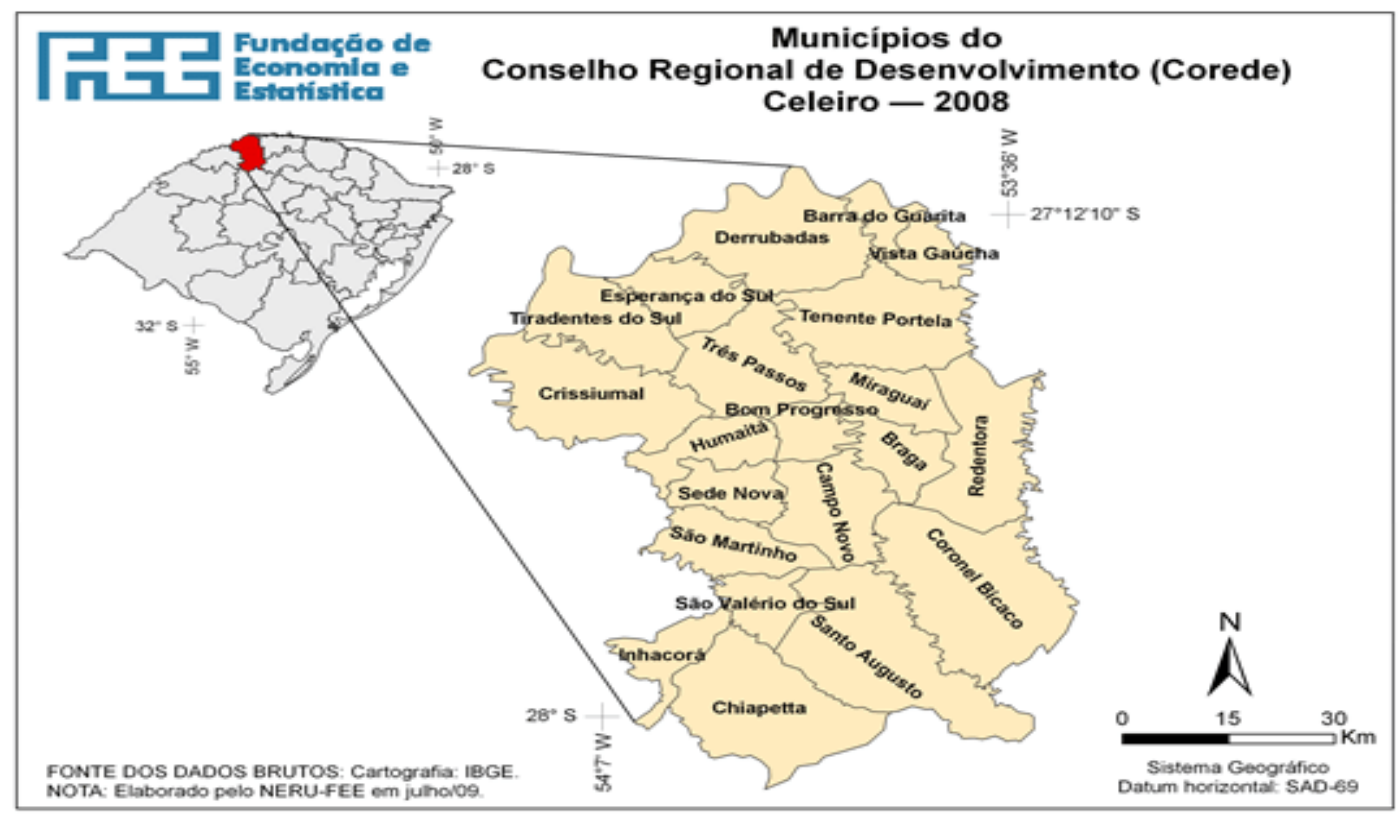

Fonte: FEE- Fundação de Economia e Estatística

O COREDE Celeiro possui uma área territorial de 4.743,00 $\mathrm{km}^{2}$, que representa $1,76 \%$ do total do Estado do Rio Grande do Sul. Segundo dados censitários de 2010, o COREDE possuía uma população de 141.482 habitantes, com relativo equilíbrio quanto à situação de domicílio, com 58\% residindo no meio urbano e $42 \%$ no meio rural. O principal centro urbano é Três Passos, com uma população de 23.965 habitantes naquele ano. Em segundo plano, aparecem Crissiumal, Santo Augusto, Tenente Portela e Redentora, com populações entre 10 e 15 mil habitantes. O restante dos municípios é de pequeno porte, com populações abaixo de 10 mil habitantes.

Segundo o relatório constante do Plano Estratégico de Desenvolvimento Regional do COREDE Celeiro do Rio Grande do Sul, 2015-2030, ao analisar os blocos do Índice de Desenvolvimento Socioeconômico - IDESE, calculados com estatísticas de 2013, pela FEERS, na relação com a média gaúcha, a região se destaca em Saúde, o índice foi de 0,8160 $($ Estado $=0,8086)$, Longevidade que apresentou o índice de 0,8750 (Estado $=0,8575) \mathrm{e}$ Educação com o índice de 0,702 (Estado = 0,6790). Já no bloco de Renda o índice com 0,647, ficou aquém do desempenho estadual, com 0,7521 naquele ano, o que já dá indícios de se tratar de uma região comprimida economicamente (RIO GRANDE DO SUL, 2017).

O COREDE Celeiro possui forte tradição nas atividades primárias voltadas para a produção de grãos, com destaque para a soja, milho e trigo e para a pecuária, com produção de leite e criação de aves e suínos. As propriedades contam com um bom nível de mecanização e uso de tecnologia e se traduzem em um grande número de pequenas propriedades familiares com produção diversificada.

Possui um Arranjo Produtivo Local (APL) fruto de política de desenvolvimento regional, sendo ligado à Agroindústria Familiar. Também apresenta uma forte cultura associativista, com grande presença de cooperativas. A Região destaca-se também pela 
produção de alimentos típicos em pequenas propriedades nas comunidades indígenas com seus costumes, língua, cultura, artesanato, entre outros (FEE, 2015).

O COREDE Celeiro possui a maior população e reserva indígena do Rio Grande do Sul, a Terra Indígena Guarita. Possui uma superfície total de 23.406,8684 ha e faz parte dos territórios dos municípios de Tenente Portela, Redentora e Erval Seco. É a maior reserva indígena em superfície territorial e populacional do Estado, possuindo aproximadamente 7.619 pessoas, segundo dados do Censo 2010, representando 40\% de toda população indígena do Rio Grande do Sul.

Na Região está localizada uma parte da Reserva da Biosfera da Mata Atlântica e o Parque Estadual do Turvo, onde se encontra a queda d'água conhecida como Salto do Yucumã, maior salto horizontal do planeta. O clima, conforme a classificação de Köppen corresponde ao subtropical temperado úmido, com nevoeiros frequentes, índices médios anuais de precipitação pluviométrica de até $1900 \mathrm{~mm}$ anuais e temperaturas com variação entre $6,6^{\circ} \mathrm{C}$ e $37,4^{\circ} \mathrm{C}$ em média (RIO GRANDE DO SUL, 2017).

Com esta breve contextualização, se entende justificada a opção amostral para representar os pequenos municípios brasileiros e, assim, dar consistência e validade à realização dos testes, cujos resultados são apresentados a seguir.

\section{RESULTADOS E DISCUSSÃO}

A Macroeconomia estuda a economia como um todo, apresenta uma visão do conjunto, o que permite analisar a determinação e o comportamento de grandes agregados. Em síntese, a "expressão agregados macroeconômicos é empregada para designar, genericamente, os resultados da mensuração da atividade econômica considerada como um todo" (ROSSETTI, 2000, p. 536).

Com esta abordagem, de conjunto, que se passa a olhar para os municípios da Região do COREDE Celeiro e, a partir da disponibilidade em cada recorte territorial, se avança para testar as estatísticas que atendem aos propósitos dessa investigação.

Assim, foram colocados em confronto os indicadores do Valor Adicionado Bruto, VAB, divulgados pelo IBGE, com os dados dos Benefícios pagos pelo INSS nos municípios da Região do COREDE Celeiro. A opção pelo VAB, que se traduz pelo resultado da equação do Produto Interno Bruto - PIB, descontados os impostos, se dá pela oportunidade de avaliação nos setores de produção: primário, que abarca as atividades agropecuária, secundário, que representa as atividades fabris, da indústria da transformação; e, terciário, que envolve as atividades de comércio e serviços, inclusive administração pública.

Nesta linha, conforme a disposição no Quadro 2, as estatísticas estão perfiladas por município e no total da região, já destacando que os valores são apresentados em mil reais e se referem ao ano de 2016. 
Quadro 2 - Valores dos VAB's Setores e Total e dos Benefícios INSS, nos municípios da Região do COREDE Celeiro/RS, no ano de 2016 (em mil reais)

\begin{tabular}{|c|c|c|c|c|c|}
\hline Municípios & VAB Total & VAB Primário & VAB Secundário & VAB Terciário & Benefícios INSS \\
\hline Barra do Guarita & 40,152 & 10,887 & 1,730 & 27,535 & 5,157 \\
\hline Bom Progesso & 53,020 & 20,079 & 2,082 & 30,860 & 4,338 \\
\hline Braga & 74,074 & 26,627 & 2,468 & 44,980 & 8,622 \\
\hline Campo Novo & 173,288 & 50,530 & 14,242 & 108,515 & 20,838 \\
\hline Chiapetta & 185,525 & 116,329 & 7,052 & 62,144 & 14,095 \\
\hline Coronel Bicaco & 292,394 & 155,233 & 14,720 & 122,441 & 23,834 \\
\hline Cirssiumal & 296,704 & 80,399 & 30,766 & 185,539 & 63,940 \\
\hline Derrubadas & 75,481 & 40,525 & 2,834 & 32,121 & 7,963 \\
\hline Esperança do Sul & 64,995 & 28,854 & 2,480 & 33,660 & 9,944 \\
\hline Humaitá & 124,967 & 46,865 & 7,051 & 71,052 & 24,233 \\
\hline Inhacorá & 57,115 & 26,850 & 1,708 & 28,558 & 4,383 \\
\hline Miraguaí & 127,342 & 36,946 & 31,004 & 59,392 & 19,197 \\
\hline Redentora & 156,424 & 66,021 & 4,435 & 85,968 & 18,958 \\
\hline Santo Augusto & 474,688 & 171,274 & 34,333 & 269,081 & 49,824 \\
\hline São Martinho & 185,679 & 68,613 & 14,375 & 102,692 & 21,884 \\
\hline São Valério do Sul & 59,042 & 33,185 & 1,981 & 23,877 & 3,092 \\
\hline Sede Nova & 84,412 & 37,850 & 3,980 & 442,583 & 4,261 \\
\hline Tenente Portela & 338,128 & 65,659 & 20,152 & 252,317 & 58,387 \\
\hline Tiradentes do Sul & 116,107 & 46,011 & 5,123 & 64,973 & 22,340 \\
\hline Três Passos & 646,972 & 74,073 & 95,674 & 477,225 & 123,919 \\
\hline Vista Gaúcha & 61,436 & 29,450 & 3,097 & 28,889 & 9,279 \\
\hline Total Região Celeiro & $3,687,945$ & $1,232,260$ & 301,287 & $2,154,402$ & 518,490 \\
\hline
\end{tabular}

Fonte: Dados secundários oficiais disponibilizados pelo INSS e IBGE

De pronto, observa-se que o município de Três Passos é, com folga, o município de maior valor agregado na Região do COREDE Celeiro, seguido de Santo Augusto e de Tenente Portela, com 646.972, 477.688 e 338.128 milhares de reais, respectivamente, no ano de 2016. Todos os demais municípios apresentaram um VAB inferior a 300 milhões de reais, o que já indica que se trata de uma Região estruturada a partir de municípios de pequeno porte em termos de geração de valor.

Para melhor dissecar esses números, o Quadro 3 apresenta a proporção relativa dos Valores Adicionados Brutos dos setores Primário, Secundário e Terciário, bem como dos Benefícios pagos pela Previdência Pública Federal no Valor Adicionado Bruto Total nos municípios e Região COREDE Celeiro.

Confirmando suas raízes na agropecuária, os números do VAB agrícola regional indicam que o setor ainda mantém sua grandeza econômica mesmo no decurso do tempo, visto registrar expressivos 33,41\% do VAB Total em 2016. Dos 21 municípios, 15 superam essa marca média regional. O município de Chiapetta, com $62,70 \%$, ponteia em desempenho relativo, em confronto com Três Passos no outro extremo, com apenas 11,45\%. 
Já o Setor Secundário aponta para a pequena representatividade da indústria nos municípios da Região, com o registro regional médio de apenas $8,17 \%$ do total, sendo que os destaques ficam por conta de Miraguaí $(24,35 \%)$, Três Passos $(14,79)$ e Crisciumal $(10,37 \%)$. Todos os demais municípios ficam com a representatividade industrial abaixo dos $10 \%$ do total das atividades econômicas, o que indica ser uma região com pouca capacidade de geração de valor, visto que o desenvolvimento da indústria da transformação em um território é decisivo no impulso econômico neste espaço geográfico.

Por sua vez, as estatísticas apontam para o Setor Terciário como o de maior valor agregado na Região, com 58,42\% de participação, o que também se confirma na maioria dos municípios, com exceção de Chiapetta, São Valério do Sul, Derrubadas, Coronel Bicaco e Vista Gaúcha, que ainda sustentam a maior grandeza no Setor Primário.

Quadro 3 - Proporção relativa dos VAB's Setores e dos Benefícios INSS no VAB Total, nos municípios da Região do COREDE Celeiro/RS, no ano de 2016

\begin{tabular}{|c|c|c|c|c|c|}
\hline Municípios & VAB Total & VAB Primário & VAB Secundário & VAB Terciário & Benefícios INSS \\
\hline Crissiumal & $100.00 \%$ & $27.10 \%$ & $10.37 \%$ & $62.53 \%$ & $21.55 \%$ \\
\hline Humaitá & $100.00 \%$ & $37.50 \%$ & $5.64 \%$ & $56.86 \%$ & $19.39 \%$ \\
\hline Tiradentes do Sul & $100.00 \%$ & $39.69 \%$ & $4.41 \%$ & $55.96 \%$ & $19.24 \%$ \\
\hline Três Passos & $100.00 \%$ & $11.45 \%$ & $14.79 \%$ & $73.76 \%$ & $19.15 \%$ \\
\hline Tenente Portela & $100.00 \%$ & $19.42 \%$ & $5.96 \%$ & $74.62 \%$ & $17.27 \%$ \\
\hline Esperança do Sul & $100.00 \%$ & $44.39 \%$ & $3.82 \%$ & $51.79 \%$ & $15.30 \%$ \\
\hline Vista Gaúcha & $100.00 \%$ & $47.94 \%$ & $5.04 \%$ & $47.02 \%$ & $15.10 \%$ \\
\hline Miraguaí & $100.00 \%$ & $29.01 \%$ & $24.35 \%$ & $46.64 \%$ & $15.08 \%$ \\
\hline Barra do Guarita & $100.00 \%$ & $27.11 \%$ & $4.31 \%$ & $68.58 \%$ & $12.84 \%$ \\
\hline Redentora & $100.00 \%$ & $42.21 \%$ & $2.84 \%$ & $54.96 \%$ & $12.12 \%$ \\
\hline Campo Novo & $100.00 \%$ & $, 29,16 \%$ & $8.22 \%$ & $62.62 \%$ & $12.03 \%$ \\
\hline São Martinho & $100.00 \%$ & $36.95 \%$ & $7.74 \%$ & $55.31 \%$ & $11.79 \%$ \\
\hline Braga & $100.00 \%$ & $35.95 \%$ & $3.33 \%$ & $60.72 \%$ & $11.64 \%$ \\
\hline Derrubadas & $100.00 \%$ & $53.69 \%$ & $3.75 \%$ & $42.56 \%$ & $10.55 \%$ \\
\hline Santo Augusto & $100.00 \%$ & $36.08 \%$ & $7.23 \%$ & $56.69 \%$ & $10.50 \%$ \\
\hline Bom Progresso & $100.00 \%$ & $37.87 \%$ & $3.93 \%$ & $58.20 \%$ & $8.18 \%$ \\
\hline Coronel Bicaco & $100.00 \%$ & $53.09 \%$ & $5.03 \%$ & $41.88 \%$ & $8.15 \%$ \\
\hline Inhacorá & $100.00 \%$ & $47.01 \%$ & $2.99 \%$ & $50.00 \%$ & $7.67 \%$ \\
\hline Chiapetta & $100.00 \%$ & $62.70 \%$ & $3.80 \%$ & $33.50 \%$ & $7.60 \%$ \\
\hline São Valério do Sul & $100.00 \%$ & $56.21 \%$ & $3.36 \%$ & $40.44 \%$ & $5.24 \%$ \\
\hline Sede Nova & $100.00 \%$ & $44.84 \%$ & $4.71 \%$ & $50.45 \%$ & $5.05 \%$ \\
\hline Total Região Celeiro & $100.00 \%$ & $33.41 \%$ & $8.17 \%$ & $58.42 \%$ & $14.06 \%$ \\
\hline
\end{tabular}

Fonte: Elaboração própria, a partir dos dados do Quadro 2

Entretanto, em obediência ao foco desta investigação, centra-se a análise na relação de valores previdenciários versus valores adicionados e, de pronto, observa-se que os benefícios repassados pela Previdência Pública Federal, enquanto Renda, são expressivos em grandeza relativa, visto que representam 14,06\% do total do Valor Agregado Bruto regional, seu indicador do Produto. Embora os benefícios não signifiquem agregação de valor via produção,

DRd - Desenvolvimento Regional em debate (ISSNe 2237-9029) 
eles somam-se à Renda Municipal/Regional, ou em outras palavras, somam-se aos rendimentos das famílias e, assim, conformam sua importância socioeconômica.

Neste quesito, vale pontuar que em Crissiumal, Humaitá, Tiradentes do Sul, Três Passos, Tenente Portela, Esperança do Sul, Vista Gaúcha e Miraguaí superaram a expressiva marca de $15 \%$ na comparação da renda agregada por benefícios com o valor agregado na produção em seus territórios. No caso de Três Passos, com 19,15\% na relação com o VAB, os benefícios superam em grande proporção a todo o produto agropecuário no município, que registrou apenas $11,45 \%$ de seu VAB Total naquele ano.

Ainda na linha do peso relativo, destaca-se que o montante das respectivas transferências públicas federais são mais representativas do que toda a agregação de valor pelas unidades industriais instaladas nos municípios, com exceção de Miraguaí, que registrou 24,35\% de VAB Secundário na totalidade da agregação bruta. No todo da Região cotejam-se $14,06 \%$ dos recursos previdenciários contra $8,17 \%$ da indústria.

Sem querer avançar em métodos estatísticos mais sofisticados de análise de comportamento de variáveis, mas com o propósito de minimamente vislumbrar sinais de conexões entre variáveis, avança-se para o testagem com recursos disponibilizados pelo Excel. O coeficiente de correlação possibilita resultados entre -1 e 1 , sendo que quanto mais próximo de -1 , maior a correlação negativa entre as variáveis, e quanto mais próximo de 1 , maior a correlação positiva. Os resultados dos testes com os Benefícios e os Valores Adicionados Brutos dos municípios da Região do COREDE Celeiro estão sintetizados no Quadro 4, a seguir.

Quadro 4 - Resultados da Correlação entre Benefícios INSS com os VAB's Setores e Total, nos municípios da Região do COREDE Celeiro/RS, no ano de 2016

\begin{tabular}{|c|c|c|c|c|}
\hline \multirow{2}{*}{ Descrição } & $\begin{array}{c}\text { Benefícios } \\
\mathrm{x} \\
\text { VAB Primário }\end{array}$ & $\begin{array}{c}\text { Benefícios } \\
\mathrm{x} \\
\text { VAB Secundário }\end{array}$ & $\begin{array}{c}\text { Benefícios } \\
\mathrm{x} \\
\text { VAB Terciário }\end{array}$ & $\begin{array}{c}\text { Benefícios } \\
\mathrm{x}\end{array}$ \\
\hline $\begin{array}{c}\text { Resultado da } \\
\text { Correlação }\end{array}$ & 0.4073935590 & 0.9326750600 & 0.9713925040 & 0.9294925990 \\
\hline
\end{tabular}

Fonte: Elaboração própria, a partir dos dados do Quadro 2

Como com um teste de correlação procura-se entender como uma variável se comporta em relação à outra, visando identificar se existe alguma relação entre a variabilidade de ambas, é possível apontar que no caso existe uma relação positiva fraca entre os benefícios previdenciários e o VAB Primário. Este resultado é plenamente esperado, visto que é difícil imaginar que a renda previdenciária possa interferir em produtividade e produção, apesar de que seria plausível inferir que a compra de insumos depende da capacidade de pagamento e que, do contrário, rendas garantidas podem desestimular atividades expostas a riscos.

De outra forma, pela grandeza dos resultados vislumbra-se de forte correlação das atividades de comércio e serviços aos recursos previdenciários repassados pela esfera federal, visto que o resultado de 0,971392504 aproxima-se do teto de 1,00. Essa constatação, de pronto já permite apontar vestígios de forte dependência dos pequenos municípios da Região do COREDE Celeiro às verbas previdenciárias, o que implica em afirmar, de outra forma, que existe uma relação direta de grandeza entre volume de recursos previdenciários e a dinâmica das atividades econômicas locais. 
Na mesma direção, embora com resultado um pouco inferior, mas também expressivo, o Setor Secundário, com 0,929492599, mostra correlação forte e pode estar sinalizando para um perfil industrial voltado para atender a demanda interna em grande parte dos municípios e, por esta razão, estar o setor também condicionado aos recursos provenientes da previdência.

A forte correlação ainda do VAB Total, com 0,929492599, traduz-se de forma inequívoca como a expressão sintetizadora do quadro referenciado por suas atividades econômicas setorizadas. Assim, já neste primeiro tratamento estatístico parece clarificada a correlação da renda recebida com o produto gerado, o que permite apontar com objetividade que os benefícios previdenciários são importantes no dimensionamento econômico local/regional.

Mesmo assim, resolveu-se avançar nos testes, em especial, para permitir a visualização gráfica destas relações. Merece reprisar que a existência, ou não, de relações entre variáveis de um processo e sua intensidade, representando duas variáveis uma em função da outra são visualizadas em um gráfico de dispersão. Com o acréscimo de uma linha de tendência se pode vislumbrar o grau de dispersão entre as combinações binárias. Já o coeficiente de determinação, $\mathrm{R}^{2}$, extraído de cálculo em regressão linear simples, pode variar no intervalo entre 0 e 1 , indicando que quanto maior o $\mathrm{R}^{2}$, mais explicativo é o modelo linear.

Feitas as marcações teórico-metodológicas, os resultados dispostos na Figura 2 propiciam a observação da plotagem dos pares, por unidade territorial, dos valores dos benefícios com os valores adicionados, respectivamente para cada setor e total, no ano de 2016 .

Figura 2 - Gráficos de dispersão relacionando os Benefícios INSS e os VAB’s Setores e Total, nos municípios da Região do COREDE Celeiro/RS, no ano de 2016

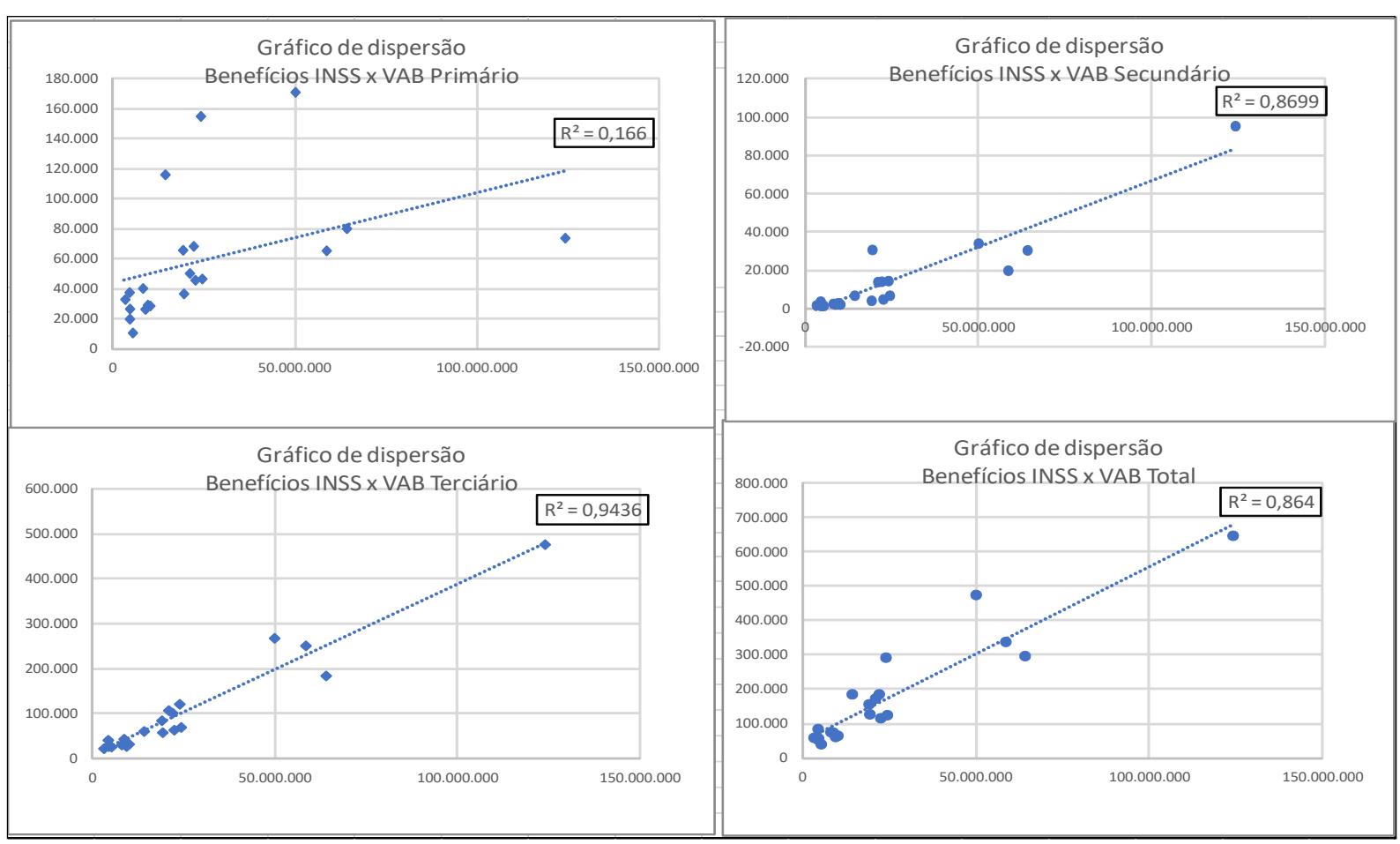

Fonte: Elaboração própria, a partir dos dados do Quadro 2 
Nos gráficos representativos do trato com as estatísticas aqui destacadas, se ratificam as tendências anteriores, pois também se observa nitidamente a maior linearidade dos Benefícios com o Setor Terciário, em contraponto a maior dispersão gráfica com o Setor Primário.

Por sua vez, o coeficiente $\mathrm{R}^{2}=0,9436$ significa que o modelo linear explica em $94,36 \%$ o desempenho da variável dependente, as atividades abarcadas nos Serviços, a partir da variável independente, as transferências de rendas previdenciárias. $\mathrm{O} \mathrm{R}^{2}$ com as atividades primárias se apresenta com apenas 0,166, que somadas aos desempenhos com o VAB Indústria, 0,8699, e com o VAB total 0,864 , dão os mesmos sinais de fumaça anteriores.

Assim, como não se objetiva precisões estatísticas, bastam aos propósitos os indicativos já elencados, que permitem registrar que se está acendendo luzes para a importância das rendas recebidas que refluem na produção local. Resta também corroborar a validade das teorias anteriormente epigrafadas, com destaque ao dimensionamento da Teoria da Base Econômica de que as atividades não básicas, no caso representadas pelos setores de produção Secundário e Terciário, são condicionadas pelo desempenho do setor básico, no caso referentes à renda recebida dos valores previdenciários.

Por fim, se entende cumprido, mas não esgotado, o objetivo primeiro desta reflexão, de sublinhar o peso econômico dos benefícios da previdência social na definição da renda nos recortes territoriais elencados e sua associação com o desempenho do produto nos pequenos municípios da Região do COREDE Celeiro.

\section{CONSIDERAÇÕES FINAIS}

O estudo procurou investigar o comportamento de variáveis agregadas, portanto macroeconômicas em nível municipal, com o intuito de identificar correlações entre rendas recebidas e o produto gerado localmente. Este tipo de investigação busca contribuir no debate sobre a dinâmica econômica dos municípios brasileiros, no sentido de qualificar a leitura da realidade local e, assim, subsidiar ações de planejamento.

Vale ainda frisar, que este foi um olhar específico da economia, em um recorte bem particular, sem adentrar em outras diferenciadas e complexas variáveis desta ou de outras disciplinas, das diversas áreas do conhecimento. Tampouco, buscou-se a precisão matemática/estatística nos resultados dos testes e, sim, indicativos de correlação entre as variáveis de Renda e Produto.

Pelos testes restou a constatação inegável de que os benefícios repassados pela Previdência Pública Federal são expressivos em grandeza relativa e conformam um delineamento importante na dinâmica econômica dos municípios da Região do COREDE Celeiro, visto que em valores relativos representam 14,06\% do total do Valor Agregado Bruto regional.

Deve-se também reforçar que, embora os recursos previdenciários não signifiquem agregação direta de valor, na rubrica da produção, eles se incorporam à Renda Municipal, por

DRd - Desenvolvimento Regional em debate (ISSNe 2237-9029) 
ampliação das disponibilidades monetárias das famílias, e, por consequência, ativam os multiplicadores das economias locais.

As fortes correlações com o Setor Terciário e Setor Secundário, nesta ordem, sinalizam pontualmente nesta direção e permitem sublinhar certas características e padrões de comportamento da produção, permitindo identificar um grau de dependência do desempenho econômico destes setores em função do ingresso dos benefícios.

De forma alguma se procura trabalhar com verdades ou análises definitivas, pelo contrário, se entende que cada apontamento merece atenção das mais variadas áreas do conhecimento, todavia, à luz das teorias referenciadas, parece restar inequívoca a grandeza econômica das transferências públicas nos municípios da Região do COREDE Celeiro, assim como são fortes os indicativos de que essa leitura pode ser amplificada para os demais municípios brasileiros.

Por fim, embora não tenha sido objeto dessa investigação, vale questionar quais os efeitos da Reforma da Previdência de 2019 na economia vindoura dos pequenos municípios brasileiros. Será que esta abordagem também foi motivo de reflexão na definição dos novos padrões previdenciários? Será que os líderes municipais que apoiaram a reforma estavam cientes das implicações aqui abordadas? O futuro nos trará as respostas.

\section{REFERÊNCIAS}

AlCÂntara, A. O.; CAMARAnO, A. A.; GiACOMIN, K. C. Política nacional do idoso: velhas e novas questões. Rio de Janeiro: IPEA, 2016.

AUGUSTO, H. A.; RIBEIRO, E. M. O envelhecimento e as aposentadorias no ambiente rural: um enfoque bibliográfico. Organizações Rurais \& Agroindustriais, v. 7, n. 2, p. 199208, maio/ago. 2005.

BRASIL. Secretaria de Previdência. Ministério da Economia. Histórico. Brasília, 15 de fev. 2019. Disponível em: $<$ http://www.previdencia.gov.br/acesso-a-informacao/institucional/his torico/>. Acesso em: 18 maio 2020.

CORREIO, R. O. M. B; CORREIO. F. A. S. D. A contribuição da previdência social rural para a redução da desigualdade de renda. Revista de Desenvolvimento Econômico-RDE, Salvador, BA, a. 17, n. 2, p. 892-914, dez. 2015.

FUNDAÇÃO DE ECONOMIA E ESTATÍSTICA DO ESTADO DO RIO GRANDE DO SUL (FEE). Perfil Socioeconômico Corede Celeiro. Porto Alegre, nov. 2015. Disponível em: $<$ http://www.fee.tche.br/sitefee/pt/content/capa/index.php>. Acesso em: 16 nov. 2019.

FUNDAÇÃO DE ECONOMIA E ESTATÍSTICA DO ESTADO DO RIO GRANDE DO SUL (FEE). Corede Celeiro. Disponível em: $<$ https://www.fee.rs.gov.br/perfilsocioeconomico/coredes/detalhe/?corede $=$ Celeiro $>$. Acesso em: 16 nov. 2019. 
GIL, A. C. Métodos e técnicas de pesquisa social. 7. ed. São Paulo: Atlas, 2019.

GUIMARÃES, J. Em 87\% das cidades do país, modelo atual de Previdência reduz a desigualdade em 2017. ANFIP, Brasília, 21 maio 2019. Disponível em:

$<$ https://www.anfip.org.br/artigo-clipping-e-imprensa/em-87-das-cidades-do-pais-modeloatual-de-previdencia-reduz-a-desigualdade>. Acesso em: 14 abr. 2020.

INSTITUTO BRASILEIRO DE GEOGRAFIA E ESTATÍSTICA (IBGE). Brasil em números. Rio de Janeiro. IBGE, 2017. v. 25.

KOHLER, R. Economia de municípios: subsídios ao diagnóstico da macroeconomia local. Saarbrücken: Novas Edições Acadêmicas, 2018. v.1.

KOHLER, R. Simulações acerca da relação entre oferta de moeda e crescimento de pequenas economias abertas. Santa Cruz do Sul: EDUNISC, 2003.

KOHLER, R.; GAY, A. L. Análise de correlação entre os setores de produção e com o produto total nos municípios gaúchos, no período de 1999 a 2012. Contribuciones a las Ciencias Sociales, Universidad de Málaga, Espanha, p. 1-13, jul. 2018. En línea: https://www.eumed.net/rev/cccss/2018/07/correlacao-setores-producao.html

NORTH, D. Teoria da localização e crescimento econômico regional. In SCWARTZMAN, J. Economia Regional. Textos escolhidos. Belo Horizonte: Cedeplar, 1977. p. 291-314.

REIS, P. R. C.; SILVEIRA, S. F. R.; BRAGA, M. J. Impactos dos benefícios previdenciários sobre o nível de bem-estar social nos municípios de Minas Gerais. In: ENCONTRO DA ANPAD; 35.4 a 7 set. 2011. Rio de Janeiro. Anais... Rio de Janeiro: ANPAD, 2011. Disponível em <http://www.anpad.org.br/diversos/down_zips/58/APB1265>. Acesso em: 18 mai. 2020. p. 01-17.

RIO GRANDE DO SUL. Secretaria de Governança e Gestão Estratégica. Planos estratégicos de desenvolvimento dos COREDEs 2015-2030: perspectivas estratégicas das Regiões Funcionais. Lajeado: Univates, 2017. Disponível em: <https://governanca.rs.gov.br/upload/ arquivos/201710/09144414-plano-sintesers.pdf>. Acesso em: 15 abr. 2020.

RIO GRANDE DO SUL. Secretaria de Planejamento, Orçamento e Gestão. VAB da Agropecuária. Disponível em: <https://atlassocioeconomico.rs.gov.br/vab-da-agropecuaria $>$. Acesso em: 08 fev. 2020.

RIO GRANDE DO SUL. Secretaria de Governança e Gestão Estratégica. Plano estratégico de desenvolvimento da Região Celeiro 2015-2030. 2017. Disponível em: $<$ https://governanca.rs.gov.br/upload/arquivos/201710/11104701-plano-celeiro.pdf $>$. Acesso em: 15 abr. 2020. p. 370.

RIO GRANDE DO SUL. Secretaria de Governança e Gestão Estratégica. Cadernos de Regionalização. Região Funcional 7. PPA 2016-2019. Disponível em: $<$ https://governanca.rs.gov.br/upload/arquivos/201512/15134146-20151117112332cadernofinal-rf7.pdf $>$ Acesso em: 10 out. 2019.

ROSSETTI, J. P. Introdução à economia. 18 ed. São Paulo: Atlas, 2000. 
SILVEIRA, R. L. L. et. al. A sociedade civil e o planejamento regional no RS/Brasil: uma análise qualitativa a partir dos COREDEs. DRd - Desenvolvimento Regional em debate, $\mathrm{v}$. 5, n. 2, p. 71-85, jul./dez. 2015.

SOUZA, N. J. Conceito e aplicação da teoria da base econômica. Perspectiva econômica, São Leopoldo, RS, v. 10, n. 25, p. 117-130, mar. 1980. 